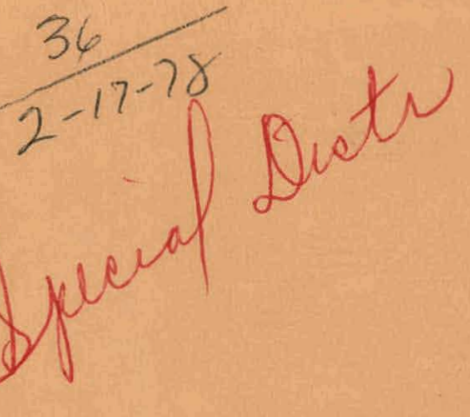

WAPD-TM-1293

DOE RESEARCH AND DEVELOPMENT REPORT

\title{
MASTER
}

\section{IN-PILE INTRAGRANULAR DENSIFICATION OF OXIDE FUELS \\ (AWBA Development Program)}

OCTOBER 1977

CONTRACT EY-76-C-11-0014 


\section{DISCLAIMER}

This report was prepared as an account of work sponsored by an agency of the United States Government. Neither the United States Government nor any agency Thereof, nor any of their employees, makes any warranty, express or implied, or assumes any legal liability or responsibility for the accuracy, completeness, or usefulness of any information, apparatus, product, or process disclosed, or represents that its use would not infringe privately owned rights. Reference herein to any specific commercial product, process, or service by trade name, trademark, manufacturer, or otherwise does not necessarily constitute or imply its endorsement, recommendation, or favoring by the United States Government or any agency thereof. The views and opinions of authors expressed herein do not necessarily state or reflect those of the United States Government or any agency thereof. 


\section{DISCLAIMER}

Portions of this document may be illegible in electronic image products. Images are produced from the best available original document. 
WAPD-TM-1293

Special External Distribution

\section{IN-PILE INTRAGRANULAR DENSIFICATION OF OXIDE FUELS (AWBA Development Program)}

C. C. Dollins and F. A. Nichols

October 1977

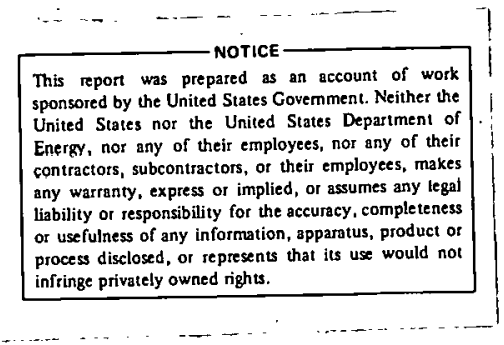

Contract EY-76-C-11-0014

Printed in the United States of America

Available from the

National Technical Information Service

U. S. Department of Commerce

5285 Port Royal Road

Springfield, Virginia 22151

NOTE

This document is an interim memorandum prepared primarily for internal reference and does not represent a final expression of the opinion of Westinghouse. When this memorandum is distributed externally, it is with the express understanding that Westinghouse makes no representation as to completeness, accuracy, or usability of information contained therein.

\section{BETTIS ATOMIC POWER LABORATORY WEST MIFFLIN, PENNSYLVANIA}

Operated for the U. S. Department of Energy by 


\section{NOTICE}

This report was prepared as an account of work sponsored by the United States Government. Neither the United States, nor the United States Department of Energy, nor any of their employees, nor any of their contractors, subcontractors, or their employees, makes any warranty, express or implied, or assumes any legal liability or responsibility for the accuracy, completeness or usefulness of any information, apparatus, product or process disclosed, or represents that its use would not infringe privately owned rights. 


\section{FOREWORD}

The Shippingport Atomic Power Station located in Shippingport, Pennsylvania was the first large-scale, central-station nuclear power plant in the United States and the first plant of such size in the world operated solely to produce electric power. This project was started in 1953 to confirm the practical application of nuclear power for large-scale electric power generation. It has provided much of the technology being used for design and operation of the commercial, central-station nuclear power plants now in use.

Subsequent to development and successful operation of the Pressurized Water Reactor in the AEC-owned reactor plant at the Shippingport Atomic Power Station, the Atomic Energy Commission in 1965 undertook a research and development program to design and build a Light Water Breeder Reactor core for operation in the Shippingport Station. In 1976, with fabrication of the Light Water Breeder Reactor (LWBR) nearing completion the Energy Research and Development Administration established the Advanced Water Breeder Applications program (AWBA) to develop and disseminate technical information which would assist U.S. industry in evaluating the LWBR concept. All three of these reactor development projects have been administered by the Division of Naval Reactors with the goal of developing practical improvements in the utilization of nuclear fuel resources for generation of electrical energy using water-cooled nuclear reactors.

The objective of the Light Water Breeder Reactor project has been to develop a technology that would significantly improve the utilization of the nation's nuclear fuel resources employing the well-established water reactor technology. To achieve this objective, work has been directed toward analysis, design, component tests, and fabrication of a water-cooled, thorium oxide fuel cycle breeder reactor to install and operate at the Shippingport Station. Operation of the LWBR core in the Shippingport Station started in the Fall of 1977 and is expected to be completed in about 3 to 4 years. Then the fissionable fuel inventory of the core will be measured. This effort, when completed in about 2 to 3 years after completion of LWBR core operation, is expected to confirm that breeding actually took place.

The Advanced Water Breeder Applications (AWBA) project was initiated to develop and disseminate technical information that will assist U.S. industry in evaluating the LWBR concept for commercial-scale applications. The project will explore some of the problems that would be faced by industry in adapting technology confirmed in the LWBR program. Information to be developed includes concepts for commercial-scale prebreeder cores which will produce uranium-233 for light water breeder cores while producing electric power, improvements for breeder cores based on the technology developed to fabricate and operate the Shippingport LWBR core, and other information and technology to aid in evaluating commercial-scale application of the LWBR concept.

Technical information developed under the Shippingport, LWBR, and AWBA projects has been and will continue to be published in technical memoranda, one of which is this present report. 


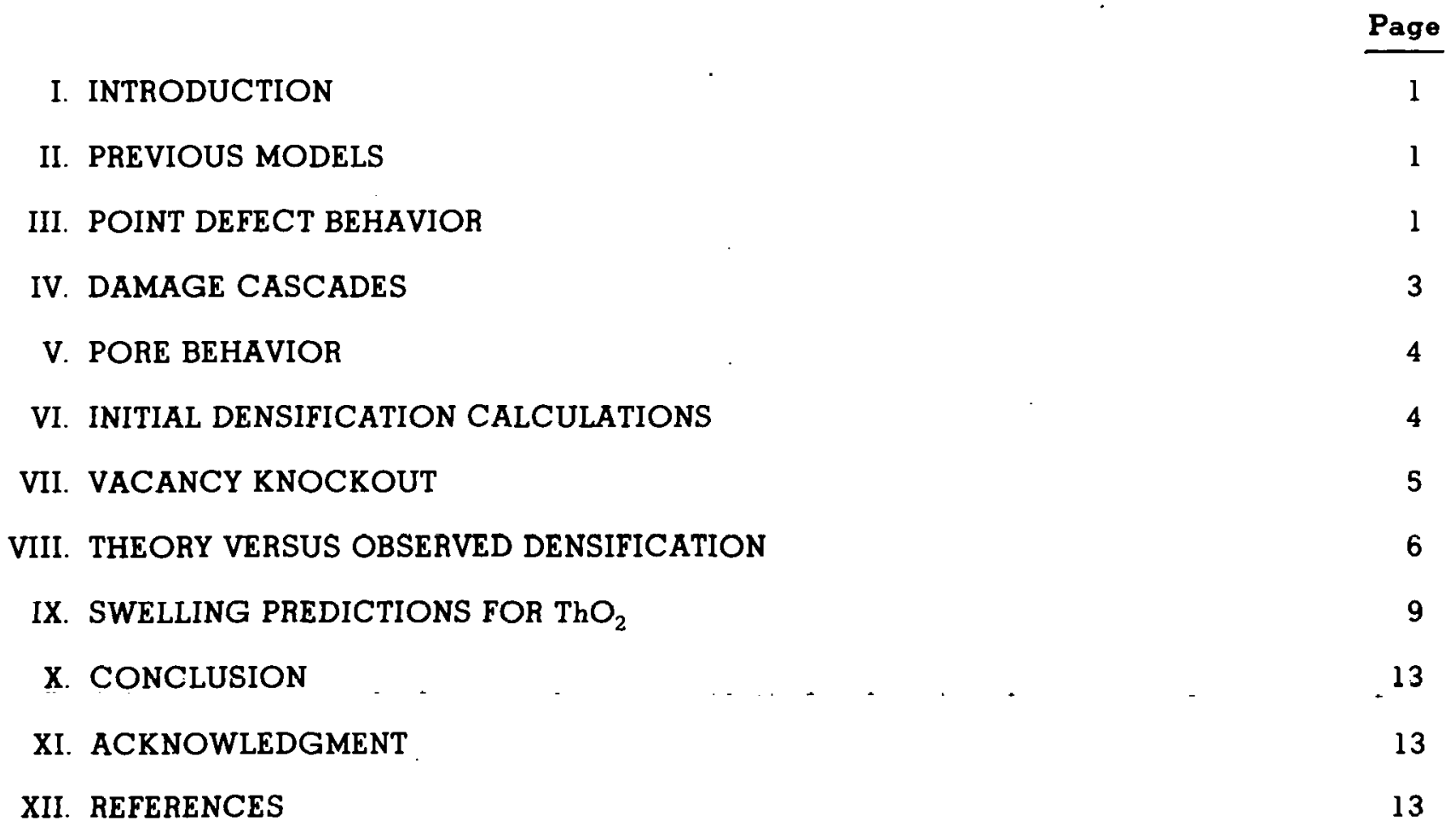

\section{LIST OF FIGURES}

$\underline{\text { Figure }}$

1 Percent Porosity versus Burnup for $\mathrm{UO}_{2}$ at Different Temperatures Assuming No Vacancy Knockout from Pores by Fission Fragments

2 Percent Porosity versus Burnup for $\mathrm{UO}_{2}$ at Different Temperatures Assuming Vacancy Knockout from Pores by Fission Fragments

3 Percent Porosity versus Burnup for $\mathrm{ThO}_{2}$ at Different Temperatures Assuming Vacancy Knockout from Pores by Fission Fragments

Comparison Between Theoretical Predictions and Reference 13 Data for Densification and Swelling in $\mathrm{UO}_{2}$

5 Comparison Between Theoretical Predictions and Swelling and Gas Release Data for $\mathrm{ThO}_{2}$

6 Model Predictions of $\mathrm{ThO}_{2}$ Swelling versus Burnup at Different Temperatures

7 Model Predictions of $\mathrm{ThO}_{2}$ Swelling versus Burnup tor Different Grain Sizes
Page

is. 


\section{NOMENCLATURE}

a

b

$\mathrm{C}_{\mathrm{g}}$

$\mathrm{C}_{\mathrm{i}}$

C。

$\mathrm{C}_{\mathrm{v}}$

D

$D_{i}$

$\mathrm{D}_{\mathrm{v}}$

$k_{i}$

k

$\mathbf{N}_{\mathrm{d}}$

$\mathrm{n}_{\mathrm{q}}$

$\mathbf{N}_{\mathrm{i}}$

N。

$\mathrm{N}_{\mathrm{p}}$

$\mathbf{P}$

$P_{g}$

$\mathbf{r}_{\mathrm{d}}$

$R_{\mathrm{g}}$

$\mathbf{r}_{\mathbf{p}}$

$\mathbf{r}_{1}$

$\Delta \mathbf{R}$

Atomic jump distance

$3.86 \times 10^{-8} \mathrm{~cm}$, Burger's vector for $\mathrm{UO}_{2} ; 3.52 \times 10^{-8} \mathrm{~cm}$ for $\mathrm{ThO}_{2}$ (Reference 15)

Fission gas concentration

Interstitial concentration

$\exp [-47000 /(\mathrm{RT})]$, thermal equilibrium vacancy concentration for $\mathrm{UO}_{2} ; \exp (-58750 / \mathrm{RT})$ for $\mathrm{ThO}_{2}$

Vacancy concentration

Fission gas diffusion coefficient

$\left(10^{13}\right)\left(3.86 \times 10^{-8}\right)^{2} \exp [-7000 /(\mathrm{RT})] / 6$, interstitial diffusion coefficient (The $7000 \mathrm{cal} / \mathrm{mole}$ for the migration energy comes from Reference 2.)

$3 \times 10^{-2} \exp [-47000 /(\mathrm{RT})] \mathrm{cm}^{2} / \mathrm{sec}$, vacancy diffusion coefficient for $\mathrm{UO}_{2} ; 3 \times 10^{-2}$ $\exp (-58750 / \mathrm{RT}) \mathrm{cm}^{2} / \mathrm{sec}$ for $\mathrm{ThO}_{2}$

Number of fission events

Fission rate

Net flux of interstitials to damage cascades per unit volume

Boltzmann's constant

Interstitial grain boundary sink strength (Reference 5)

Vacancy grain boundary sink strength

Damage cascade density

Number of gas atoms in a pore

Net number of interstitials

$\mathbf{\Omega}^{-1}=$ Number of lattice sites per unit volume

Pore density

Externally applied hydrostatic pressure .

Pressure due to gas in the pores

Damage cascade radius

Grain or subgrain radiue

Pore radius

Half the distance between dislocations

Increased capture radius of a dislocation for an interstitial 


\section{NOMENCLATURE (Cont)}

\section{Symbol}

$\mathrm{T}$

$\mathrm{V}_{\mathrm{p}}$

$\beta$

$\gamma$

$\boldsymbol{\epsilon}$

$\eta$

$\lambda$

$\mu$

$\nu$

$\rho$

$\tau$

$\Omega$
Definition

Absolute temperature

Pore volume

$6.97 \times 10^{-23} \mathrm{~cm}^{3} /$ atom, van der Waals' constant (Reference 17)

626 ergs $/ \mathrm{cm}^{2}$, surface energy for $\mathrm{UO}_{2} ; 775 \mathrm{ergs} / \mathrm{cm}^{2}$ for $\mathrm{ThO}_{2}$ (Reference 16)

Size misfit parameter of interstitial in lattice

Number of vacancies which escape a collision between a fission fragment and a pore

Viable fission fragment track length

$7.2 \times 10^{11}$ dynes $/ \mathrm{cm}^{2}$, shear modulus (Reference 15 )

0.30 , Poinoon'o oonctant

Number of vacancies escaping two damage cascades

Dislocation density

Mean slay time of atoms between fission displacement events

$4.1 \times 10^{-23} \mathrm{~cm}^{3}$, atomic volume for $\mathrm{UO}_{2} ; 4.38 \times 10^{-23} \mathrm{~cm}$ for $\mathrm{ThO}_{2}$ (Reference 15) 
This report proposes a model to describe in-pile densification of oxide fuels, by both vacancy boil-off due to thermal excitation and vacancy knockout by the passage of fis. sion fragments through the pores. The model includes the migration rates of both vacancies and interstitials to pores and the production of vacancy-rich damage cascades by fission fragments. It has been coupled with a previously reported swelling and gas release model so that it can predict the total dimensional changes of the fuel as well as predicting intragranular densification for both $\mathrm{ThO}_{2}$ and $\mathrm{UO}_{2}$ fuels for advanced water breeder reactor applications development effort.

\title{
IN-PILE INTRAGRANULAR DENSIFICATION OF OXIDE FUELS (AWBA Development Program)
}

\author{
C. C. Dollins and F. A. Nichols
}

\section{INTRODUCTION}

This report proposes a model to describe in-pile intragranular densification of oxide fuels by both vacancy boil-off due to thermal excitation and vacancy knockout by the passage of fission fragments through the pores. Since only intragranular densification is considered, the model is limited to porosity less than about 7 percent. The model includes migration of both vacancies and interstitials to pores and the production of vacancy-rich damage cascades by fission fragments. Experimental results indicate that at temperatures above approximately $1400 \mathrm{C}$ densification takes place by vacancy boil-off. At temperatures below about $1300 \mathrm{C}$ the densification rate is independent of the temperature and is due to vacancy knockout by fission fragments. Comparisons have also been made between model predictions and experimental data for decrease in pore size with time and increase in density with time, both with good agreement.

\section{PREVIOUS MODELS}

Reference l proposes an in-pile densification model based on the assumption that fission fragments passing through an intragiauular puse can knock vacancies from the pore. The vacancy concentration at the pore is higher than the equilibrium concentration, while the vacancy concentration at the grain boundaries is assumed to be in thermodynamic equilibrium. Therefore, the vacancy concentration at the grain boundaries is at a lower chemical potential than at the pore surface, and this chemical potential difference drives the vacancies from the pore to the grain boundaries. Huwever, this model does not include the effect of dislocations as sinks nor does it consider the fact that fissioning produces vast concentrations of interstitials and vacancies at damage cascades. Therefore, it does not consider the controlling. influence this point defect production exerts on interstitial and vacancy concentrations.
Reference 2 also proposes a model for determining in-pile densification. While it does consider the production of point defects at damage cascades, it assumes that vacancies and interstitials are produced in equal numbers and migrate to grain boundaries, dislocations, and pores. Since interstitials diffuse much more rapidly than vacancies, a far larger number of interstitials reach the pores at early times than vacancies. This dominance of interstitial migration acts to heal the pores; thus it must be included in the densification calculations.

The present work includes vacancy knock-out by fission fragments and point defect loss to damage cascades not considered in Reference 2 . Also included are point defect generation and loss at damage cascades, point defect loss to dislocations, and the effect of interstitials not considered in Reference 1.

\section{POINT DEFECT BEHAVIOR}

The fissioning of an atom produces two highly energetic fission fragments which lose energy, first by ionizing the lattice atoms, and then by knocking the lattice atoms out of the lattice sites. The regions of displaced atoms or damage cascades consist of vacancy clusters surrounded by isolated interstitials and a few isolated vacancies. At the relatively high temperatures of interest, microannealing takes place, and the vacancy clusters can agglomerate and collapse into vacancy dislocation loops. It will be assumed here that one loop is formed for each fission fragment created, although in reality several loops are expected to form along the fragment path. The vacancy cluster configuration has a very small ettect on the point defect behavior because of its low density.

A large fraction of the interstitials migrate back to the damage cascade from which they originated. It will be assumed here that about 10 percent of the interstitials created escape the damage cascade and become free to migrate through the 
lattice. Since $10^{5}$ atomic displacements are created per fission event and each fission event results in two damage cascades, about $10^{4}$ interstitials are assumed to escape each damage cascade. In this model the two damage cascades are assumed to be equal. The number of vacancies escaping per fission event is given by

$$
\xi=10^{4}-2 \frac{\pi r_{d}^{2} b}{\Omega}
$$

where $r_{d}$ is the radius of the collapsed vacancy loop, $b$ is the Burger's vector of the loop, and $\Omega$ is the atomic volume. (See Nomenclature for a complete list of symbols and constants.) The coefficient 2 in Equation ( 1 ) comes from the assumption that two damage cascades result from a fission event.

The point defects once created can migrate to and he ahsorbed at dislocations, fabricated pores (henceforth called pores), damage cascades (treated as loops), grain or subgrain boundaries, and fission gas bubbles (not treated as nor called pores). The point defects can also be destroyed by mutual recombination. The net absorption of interstitials at pores is what leads to densification and is what is described by the Reference 2 model. The calculation of the net arrival rate of interstitials to pores is the main concern in Sections III, IV, and V. Vacancy knockout by fission fragments will be discussed in Section VII.

The loss rate of vacancies to dislocations as given in Reference 3 is equal to

$$
\frac{2 \pi \rho D_{\mathrm{v}}}{\ln \left(\mathrm{r}_{1} / \mathrm{b}\right)}\left(\mathrm{C}_{\mathrm{v}}-\mathrm{C}_{0}\right)
$$

where

$$
\begin{aligned}
\rho= & \text { dislocation density } \\
\mathrm{D}_{\mathrm{v}}= & \text { vacancy diffusion coefficient } \\
\mathrm{C}_{\mathrm{v}}= & \text { average vacancy concentration far from } \\
& \text { the dislocation } \\
\mathrm{C}_{\mathrm{v}}= & \text { thermal equilibrium vacancy concentra- } \\
& \text { tion } \\
\mathrm{r}_{1}= & \text { half the distance between dislocations } \\
& (1 / \sqrt{\pi \rho}) .
\end{aligned}
$$

The dislocation density as a function of temperature is given by Relerence 4 as

$\rho=\exp \left(-2.07 \times 1 \mathrm{G}^{-3}(\mathrm{~T}-273)+21.82\right)$,

where $\mathrm{T}$ is the absolute temperature and the dislocation density is in units of $\mathrm{cm}^{-2}$.

The loss rate of vacancies to pores given by Reference 3 is

$$
\begin{aligned}
4 \pi r_{p} N_{p} & D_{v}\left\{C_{v}\right. \\
& \left.-C_{0} \exp \left[\frac{\Omega}{k T}\left(\frac{2 \gamma}{r_{p}}+P-P_{g}\right)\right]\right\},
\end{aligned}
$$

where

$$
\begin{aligned}
r_{p}= & \text { pore radius (for simplicity only one pore } \\
& \text { size is considered) } \\
N_{p}= & \text { number of pores per unit volume } \\
\mathbf{k}= & \text { Boltzmann's constant } \\
\gamma= & \text { surface tension of the pore } \\
\mathrm{P}= & \text { externally applied hydrostatic pressure } \\
\mathrm{P}_{\mathrm{g}}= & \text { pressure due to any fission gas that has ac- } \\
& \text { cumulated in the pore. }
\end{aligned}
$$

The loss rate of vacancies to damage cascades is given by Reference 3 as

$$
\begin{aligned}
4 \pi^{2} r_{d} N_{d} D,\left\{C_{v}\right. \\
\left.-C_{0} \exp \left[-\frac{\mu b \ln \left(32 r_{d} / b\right)}{4 \pi(1-\nu) r_{d} k T}\right]\right\} / \ln \left(O_{i_{d}} / b\right),
\end{aligned}
$$

where

$$
\begin{aligned}
\mathbf{r}_{\mathrm{d}} & =\text { damage cascade radius } \\
\mathrm{N}_{\mathrm{d}} & =\text { number of cascades per unit volume } \\
\mu & =\text { shear modulus } \\
\nu & =\text { Poisson's constant. }
\end{aligned}
$$

The loss rate of vacancies to grain or subgrain boundaries is given by Reference 5 as

$$
\frac{3 k_{v} D_{v}}{R_{g}}\left(C_{v}-C_{0}\right)
$$

where $R_{g}$ is the radius of the grain or subgrain and $k_{v}$ is given by Reference 5 as

$$
\mathrm{k}_{\mathrm{v}}=\left[\frac{2 \pi \rho}{\ln \left(\mathrm{r}_{1} / \mathrm{b}\right)}+4 \pi\left(\mathrm{r}_{\mathrm{p}} \mathrm{N}_{\mathrm{p}}+\mathrm{r}_{\mathrm{d}} \mathrm{N}_{\mathrm{d}}\right)\right]^{\frac{1}{2}}
$$

The loss rate through recombination with interstitials from Reference 3 is

$$
\frac{5040\left(D_{i}+D_{v}\right)}{a^{2}} C_{v} C_{i}
$$

where $C_{i}$ and $D_{i}$ are the interstitial concentration and diffusion coefficient, respectively, and $a$ is the atomic jump distance.

The loss rate of vacancies to gas bubbles is difficult to calculate because the arrival of vacancies affects the energy of the gas.* However, in-pile

\footnotetext{
* Consider an isolated gas atom or even a few gas atoms in a very small bubble. If a vacancy arrives at this bubble, the volume of the bubble increases, the pressure drops, and the free energy of the vacancies within the bubble increases. It is unlikely that another vacancy can join the bubble until the bubble emits a vacancy or until an interstitial is absorbed; therefore, the very small bubble acts as a recombination site.
} 
densification of intragranular pores is usually finished by a depletion of 1 to $2 \times 10^{20} \mathrm{t} / \mathrm{cm}^{3}$ (References 2 and 6 ), and it is not necessary to calculate densification over a range of fission densities higher than this value. Up to this depletion and at temperatures below approximately $900 \mathrm{C}$, fission gas remains as isolated gas atoms in $\mathrm{UO}_{2}$ and is not in bubbles (Reference 7). Isolated gas atoms would behave as any other impurity atom and would serve as trapping sites only and not as sink sites for point defects. Large gas bubbles may serve as sink sites, while an interstitial would still be required to annihilate a vacancy. It is assumed that recombination at a trap site is included in the term given by Equation ( 8 ). At temperatures above $900 \mathrm{C}$, the vacancy concentration is approximately $\mathrm{C}_{0}$, so loss to large bubbles would not affect the vacancy concentration. Thus, the vacancy absorption at bubbles containing fission gas is not calculated (negligible effect) for this application. The same argument would hold for other oxide fuels, say $\mathrm{ThO}_{2}$, but at relatively higher temperatures.

By the use of Equations (2), (4), (5), (6), and (8) it can be shown that the rate of change in the vacancy concentration is given by

$$
\begin{aligned}
\frac{d C_{v}}{d t}= & \dot{f} \Omega \xi-\frac{2 \pi \rho D_{v}}{\ln \left(\mathrm{r}_{1} / b\right)}\left(C_{v}-C_{o}\right)+4 \pi r_{p} N_{p} D_{v} \\
& \left\{C_{o} \exp \left[\frac{\Omega}{k T}\left(\frac{2 \gamma}{r_{p}}+P-P_{q}\right)\right]-C_{v}\right\} \\
& +4 \pi^{2} r_{d} N_{d} D_{v}\left\{C_{o} \exp \left(+\frac{\mu b \Omega \ln \left(32 r_{d} / b\right)}{4 \pi(l-\nu) r_{d} k T}\right)\right. \\
& \left.-C_{v}\right\} / \ln \left(\frac{8 r_{d}}{b}\right)-\frac{5040\left(D_{i}+D_{v}\right)}{a^{2}} C_{v} C_{i} \\
& -\frac{3 k_{v} D_{v}}{R_{g}}\left(C_{v}-C_{o}\right),
\end{aligned}
$$

where $\dot{f}$ is the fissinn rate.

An equation similar to Equation (9) exists for interstitials. It is given by

$$
\begin{aligned}
\frac{d C_{i}}{d t}= & i \Omega 10^{4}-\frac{2 \pi D_{i} C_{i} \rho}{\ln \left(r_{1} /(b+\Delta R)\right)} \\
& -4 \pi r_{p} N_{p} D_{i} C_{i}=4 \pi^{2} r_{d} N_{d} D_{i} C_{i} / \ln \left(\frac{8 r_{d}}{b}\right) \\
& -\frac{5040\left(D_{i}+D_{v}\right) C_{v} C_{i}}{a^{2}}-\frac{3 k_{i} D_{i} C_{i}}{R_{g}},
\end{aligned}
$$

$\mathrm{k}_{\mathrm{i}}=\left[\frac{2 \pi \rho}{\ln \left(\mathrm{r}_{1} /(\mathrm{b}+\Delta \mathrm{R})\right)}\right]+4 \pi\left(\mathrm{r}_{\mathrm{p}} \mathrm{N}_{\mathrm{p}}+\mathrm{r}_{\mathrm{d}} \mathrm{N}_{\mathrm{d}}\right)^{\frac{1}{2}}$

and $\Delta R$, the increased capture radius of a dislocation for an interstitial, is given by References 8 and 9,

$$
\Delta \mathrm{R}=0.07 \mathrm{~b} \mathrm{a}^{3} \mu \epsilon / \mathrm{kT},
$$

where $\epsilon$ is the size misfit parameter of an interstitial in the lattice.

Equations (9) and (10) thus yield the background concentrations of vacancies and interstitials, respectively. These equations will be used later in the determination of overall densification.

\section{DAMAGE CASCADES}

In the present work, as was done in the case of depleted zones in Zircaloy (Reference 3 ), it is assumed for simplicity that there is only one size of damage cascade. The size would be the average size of the cascade over its lifespan. The number of vacancies in such a cascade would be approximately half the number present when the cascade was created. If it is assumed that all the vacancies are in the cascade cluster at creation (approximately $0.5 \times 10^{4}$ ), the average cascade would have about half that number at midlife, or approximately 2500 vacancies. The effective isolated vacancy generation rate would then be $\xi=5000$, and the cascade loop radius would be given by

$$
r_{d}=\left(\frac{2500 \Omega}{\pi b}\right)^{\frac{1}{2}}
$$

Since a cascade increases in size by absorbing vacancies, it decreases in size by absorbing interstitials and emitting vacancies. This net flux of interstitials to damage cascades per unit volume is given by

$$
\begin{aligned}
J= & 4 \pi^{2} r_{d} N_{d} N_{o} / \ln \left(8 r_{d} / b\right)\left\{D_{i} C_{i}+D_{v}\right. \\
& {\left.\left[C_{o} \exp \left(-\frac{\mu b \Omega \ln \left(32 r_{d} / b\right)}{4 \pi(1-\nu) r_{d} k T}\right)-C_{v}\right]\right\}, }
\end{aligned}
$$

where $N_{0}$ is the number of lattice sites per unit volume.

The net number of interstitials to fill all cascades is given by

$$
\mathrm{N}_{\mathrm{i}}=\frac{\pi \mathrm{r}_{\mathrm{d}}^{2} \mathrm{~b} \mathrm{~N} \mathrm{~N}_{\mathrm{d}}}{\Omega}
$$


The rate (number per second) that cascades are filled is found by dividing Equation (15) by Equation (14). The change in the number of cascades due to filling is the number of cascades divided by the rate at which they are filled. The rate that cascades are created is $2 \dot{f}$. The rate of change in the number of cascades is then given by

$$
\begin{aligned}
\frac{\mathrm{dN} N_{d}}{d t}= & 2 \dot{f}-\frac{N_{d} 4 \pi}{r_{d} b \ln \left(8 r_{d} / b\right)}\left\{D_{i} C_{i}+D_{v}\right. \\
& {\left[C_{0} \exp \left(-\frac{\mu b \Omega \ln \left(32 r_{d} / b\right)}{4 \pi(l-\nu) r_{d} k T}\right)\right.} \\
& \left.\left.-C_{v}\right]\right\}
\end{aligned}
$$

\section{PORE BEHAVIOR}

Pores, as in the case of damage cascades, grow by absorbing vacancies; they shrink by absorbing interstitials and emitting vacancies. Letting $n_{p}$ be tho number of interstitials it takes to fill a pore, the net flux of interstıtıals to the pore is given by

$$
\begin{aligned}
\frac{d n_{p}}{d t}= & 4 \pi r_{p} N_{o} D_{i} C_{i}+4 \pi r_{p} N_{o} D_{v} \\
& \left\{C_{o} \exp \left[\frac{\Omega}{k T}\left(\frac{2 \gamma}{r_{p}}+P-P_{g}\right)\right]-C_{v}\right\} .
\end{aligned}
$$

The volume of a pore, $V_{p}$, is related to the pore radius and the number of interstitials required to fill the pore by the equation

$$
\mathrm{V}_{\mathrm{p}}=\frac{4}{3} \pi \mathrm{r}_{\mathrm{p}}^{3}=\mathrm{n}_{\mathrm{p}} \Omega
$$

so that

$$
\frac{\mathrm{dV}_{\mathrm{p}}}{\mathrm{dt}}=\Omega \frac{\mathrm{dn}_{\mathrm{p}}}{\mathrm{dt}}=4 \pi \mathrm{r}_{\mathrm{p}}^{2} \frac{\mathrm{dr}_{\mathrm{p}}}{\mathrm{dt}}
$$

'l'heretore

$$
\begin{aligned}
\frac{d r_{p}}{d t}= & -\frac{1}{r_{p}}\left[D_{i} C_{i}+D_{v}\left\{C _ { o } \operatorname { e x p } \left[\begin{array} { c } 
{ \Omega } \\
{ k T }
\end{array} \left(\begin{array}{l}
2 \gamma \\
I_{p}
\end{array}\right.\right.\right.\right. \\
& \left.\left.\left.\left.+P-P_{q}\right)\right]-C_{v}\right\}\right] .
\end{aligned}
$$

The pressure of the gas in the pore, $P_{g}$, is calculated from a simplified van der Waals' gas law and is given by

$$
\mathrm{P}_{\mathrm{g}}=\frac{\mathrm{n}_{\mathrm{g}} \mathrm{kT}}{\frac{4}{3} \pi \mathrm{r}_{\mathrm{p}}^{3}-\beta \mathrm{n}_{\mathrm{g}}},
$$

where $\beta$ is van der Waals' gas constant and $n_{g}$ is the number of gas atoms in the pore. The change in the number of gas atoms in a pore with respect to time is given by

$$
\frac{d n_{g}}{d t}=4 \pi r_{p} D C_{g} N_{o}-\frac{n_{g}}{\tau},
$$

where $D$ is the fission gas diffusion coefficient and $\mathrm{C}_{\mathrm{g}}$ is the fission gas concentration, which is a function of temperature, depletion, grain size, etc. The first term on the right hand side of Equation (20) is the rate at which gas migrates to the pore, and the second term is the rate at which it is knocked out by fission fragments passing through the pore. The form of the second term was taken from Reference 10. $\tau$ is the mean stay time of atoms in the system between fission fragment displacement events and is given by Reference 11 as

$$
\tau=\left(10^{5} \Omega \dot{\mathrm{i}}\right)^{-1},
$$

where $10^{5}$ ie the total number of displacements. Very early $\mathrm{C}_{g}$ is essentially zero. Therefore, $\mathrm{n}_{g}$ and $P_{y}$ are esseulially zero and, hcnoo, aro unimportant when calculating the change in the pore radius with respect to time. After a time $\tau$ (approximately 10 hours), Equation (20) reaches a steady state value, so that the gas may be assumed to be at steady state in the pores for the remaining calculations. Therefore,

$$
\mathrm{n}_{\mathrm{g}}=4 \pi \mathrm{r}_{\mathrm{p}} \mathrm{DC}_{\mathrm{g}} \mathrm{N}_{\mathrm{o}} \tau
$$

\section{INITIAL DENSIFICATION CALCULATIONS}

At this point there are four equations (Equatinns (4), (10), (16), and (18)) dnd luus unknowns $\left(\mathcal{C}_{v}, \mathcal{C}_{i}, N_{d}\right.$, and $\left.r_{p}\right)$ which cau be solved simultano. ously. These equations must be coupled with the swelling and gas release model (Reference 12) to obtain the fission gas concentration $\left(C_{g}\right)$ and the fission gas diffusion coefficient (D). Since the interstitials diffuse very rapidly al the lemperature of interest, it is assumed that they are in steady state equilibrium; thus, $d C_{i} / d t$ can be set equal to zero. With $d \Gamma_{1} / d_{\dagger}=0$, Equations (9), (10), (16), and (18) were solved with the initial conditions that $C_{\text {v }}$ $=\mathrm{C}_{0}, \mathrm{~N}_{d}=0$, and $\mathrm{r}_{\mathrm{p}}=10^{-4} \mathrm{~cm}$. It was found that, with the large production rate of interstitials $\left(10^{17} / \mathrm{cm}^{3}\right.$ 3cc with a lission iate $10^{13} / / \mathrm{cm}^{3}$ oeo) and with the somewhat smaller production rate of vacancies, the interstitials impose a steady state concentration on the vacancies far sooner than if the vacancies approached steady state through their own diffusinn. The vacancies reached steady state in less than a second at temperatures down to 200C. Because of the rapid approach of vacancies to steady state, $\mathrm{d} \mathrm{C}_{\mathrm{v}} / \mathrm{dt}$ can also be set equal to zero. This result is very different from that presented in Reference 2, where equal production 
rates of vacancies and interstitials were assumed. In that case, approximately $10^{6}$ seconds were needed for a steady state concentration of vacancies to be reached at $900 \mathrm{~K}$.

Equations (9), (10), and (18) were solved assuming both $\mathrm{dC}_{\mathrm{v}} / \mathrm{dt}$ and $\mathrm{dC}_{\mathrm{i}} / \mathrm{dt}$ equal to zero. The densification model was coupled to the swelling and gas release model (Reference 12 ) and the resulting porosity as a function of burnup was predicted based on a fission rate of $10^{13} \mathrm{f} / \mathrm{cm}^{3} \mathrm{sec}$, a grain diameter of $10 \mu \mathrm{m}$, initial pore diameter of $5 \mu \mathrm{m}$, and a pore density of $109 / \mathrm{cm}^{3}$. The results are shown in Figure 1 for several temperatures of $\mathrm{UO}_{2}$. They indicate that densification drops off quite rapidly with temperature and that the porosity actually increases at $1000 \mathrm{C}$ and $1100 \mathrm{C}$. Below $1000 \mathrm{C}$ densification does not take place.

These results are contrary to observation. Reference 6 notes that at $200 \mathrm{C} 0.5 \mu$ pores in $\mathrm{UO}_{2}$ heal by a depletion of $3 \times 10^{19} \mathrm{t} / \mathrm{cm}^{3}$. In Reference 13 it was observed that in $\mathrm{UO}_{2}$ specimens in which most of the pores were smaller than $2 \mu \mathrm{m}$ in diameter although a number were greater than $10 \mu \mathrm{m}$, the densification reached a maximum at a depletion of about $10^{20} \mathrm{f} / \mathrm{cm}^{3}$ at temperatures below 700C. This would indicate that thermal diffusion alone is not sufficient to explain the healing of pores and that the model described above must be modified.

\section{VACANCY KNOCKOUT}

Reference 1 notes that when a fission fragment passes through a pore, the resulting disruption can knock vacancies from the pore to the lattice. Some of the vacancies diffuse away from the pore to other sinks, and the pore shrinks. The exact details of such a knocking process are most likely very complicated and no attempt will be made here to discuss them. What is needed is an estimate of the number of times per second a pore is hit by a fission fragment and the number of vacancies that escape per hit (this will be called $\eta$ ). The number of hits per second is equal to the number of fission fragments produced per second, times the volume around each pore through which the fragment can travel and remove vacancies from the pore, times the number of pores. The number of fission fragments produced per second is $2 \dot{f}$, and the total volume in which they can cause vacancies to leave the pore is $4 \pi r_{p}^{2} N_{p} \lambda$, where $\lambda$ is the "viable" length of the fission fragment path. Immediately

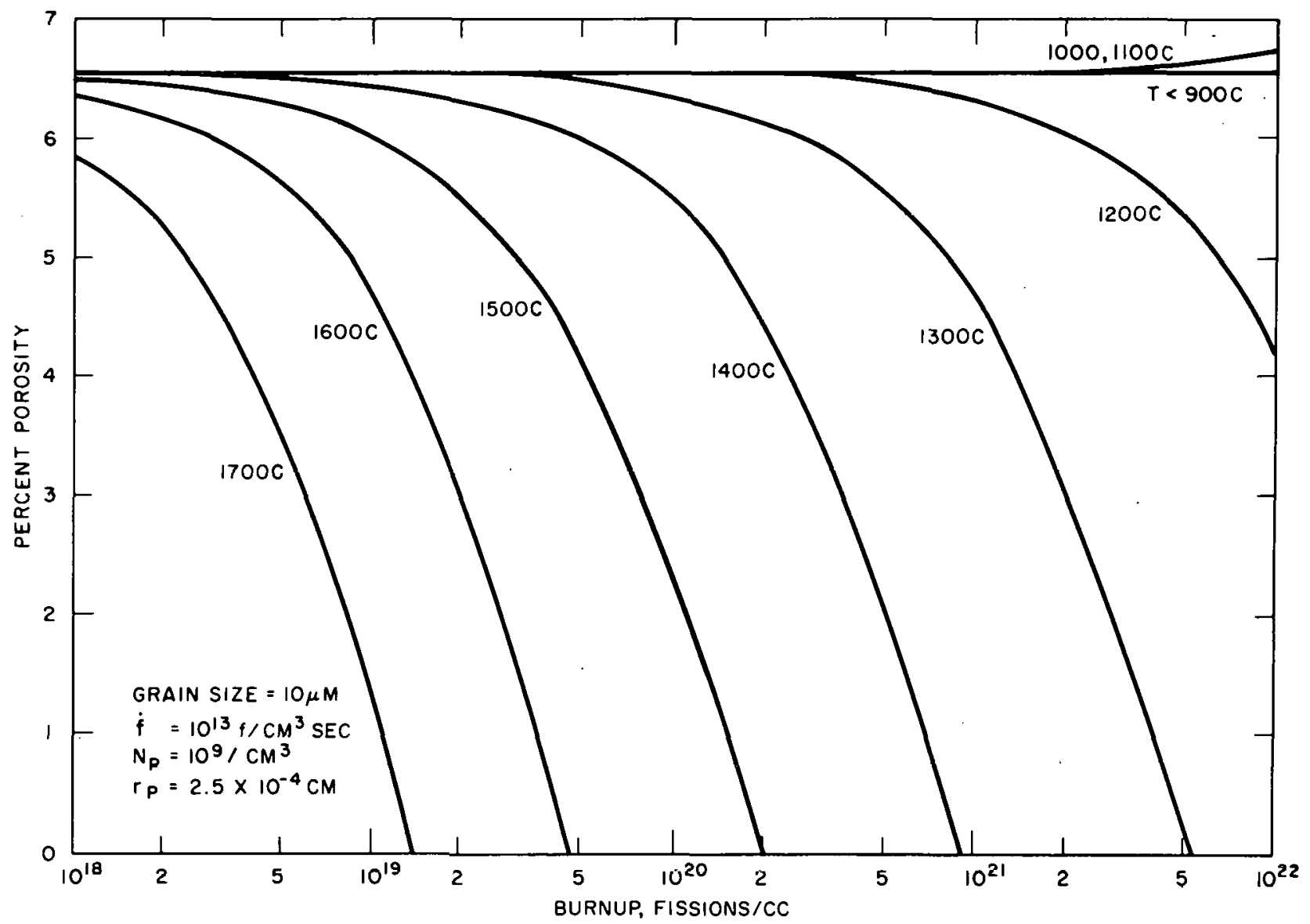

Figure 1. Percent Porosity versus Burnup for $\mathrm{UO}_{2}$ at Different Temperatures Assuming No Vacancy Krockout from Pores by Fission Fragments 
after a fragment is created its energy is too great to cause displacements; however, during the last 10 percent of the path length (approximately) the energy is low enough to cause displacements. This is the "viable" path length. Since the total path length is about $10 \mu$, the viable path length is about $1 \mu$.

The probability that a particular pore is hit by a fragment is

$$
2 \dot{\mathrm{f}} 4 \pi \mathrm{r}_{\mathrm{p}}^{2} \lambda .
$$

If the number of vacancies knocked out of a pore per collision is $\eta$ (assumed to be approximately 100), the number of vacancies knocked out of the pore per second will be

$$
2 \dot{f} 4 \pi r_{\mathrm{p}}^{2} \lambda \eta \text {. }
$$

It is an easy matter to show that the change in the pore radius with respect to time is given by

$$
\frac{d r_{y}}{d t}=-\$ 22 \dot{i} \lambda \eta \text {. }
$$

The total change in the pore radius with respect to time is now given by adding Equation (22) to Equation (18). The vacancy production rate from the pores is given by

$$
\frac{\mathrm{dC}}{\mathrm{dt}}=8 \pi \dot{\mathrm{f}} \mathrm{r}_{\mathrm{p}}^{2} \lambda \eta \mathrm{N}_{\mathrm{p}} \Omega
$$

The vacancy production rate given by Equation (23) must now be added to Equation (9) to get the total change in the vacancy concentration with respect to time.

The results of the addition of Equations (22) and (23) to Equations (18) and (19) are shown in Figure 2 , which is a plot of porosity versus depletion for $\mathrm{UO}_{2}$ for the same conditions as used in the predictions of Figure 1. At temperatures greater than $1600 \mathrm{C}$ the fission-induced resolution of the pores has little effect on decreasing the porosity. At temperatures below $1300 \mathrm{C}$ the densification rate is independent of temperature. A similar plot showing estimates for a $\mathrm{ThO}_{2}$-base fuel is shown in Figure 3. In the case of $\mathrm{ThO}_{2}$, densification is independent of temperatures below about $1600 \mathrm{C}$. $\mathrm{ThO}_{2}$ melts at a temperature about 25 percent higher than $\mathrm{UO}_{2}$. Therefore, the activation energies of the parameters used for $\mathrm{ThO}_{2}$ were assumed to be 25 percent larger for $\mathrm{ThO}_{2}$.

\section{THEORY VERSUS OB. SERVED DENSIFICATION}

Comparing theory with experiment is difficult because porosity in actual specimens is not limited to intragranular porosity. The porosity associated with the grain boundaries is usually much larger (Reference 13) and is consequently expected to heal much more slowly. In Reference 6 $\mathrm{UO}_{2}$ was irradiated at $200 \mathrm{C}$, and pores that were initially $0.5 \mu \mathrm{m}$ in diameter were observed to disappear after a burnup of $2.9 \times 10^{19} \mathrm{f} / \mathrm{cm}^{3}$. Assuming a fission rate of $10^{13} \mathrm{f} / \mathrm{cm}^{3}$ sec, a grain radius of $10^{-4} \mathrm{~cm}$, and a pore density of $10^{12} / \mathrm{cm}^{3}$, the model predicts that a pore $0.5 \mu \mathrm{m}$ in diameter will disappear at a burnup of $3 \times 10^{19} \mathrm{f} / \mathrm{cm}^{3}$ when $\lambda=10^{-4} \mathrm{~cm}$ and $\eta=100$. This is very good confirmatinn of the liw-temperature portion of tho theory. Additional confirmation comes from Reference 13, where $\mathrm{UO}_{2}$ was fissioned at rates between $2.9 \times 10^{11}$ and $4.4 \times 10^{12} \mathrm{f} / \mathrm{cm}^{3} \mathrm{sec}$ at center line temperatures between 360 and $1133 \mathrm{C}$. Tho initial porosity was 3.65 percent, and the results after fissioning are shown in Figure 4. The initial structure contained a number of pores $10 \mu \mathrm{m}$ and a good deal of porosity less than $2 \mu \mathrm{m}$ in diameter. The quantity of each porosity was not given, but the densification model used to predict the curve of Figure 4 assumed an initial pore radiua of $1 \mu \mathrm{m}$ and a pore density of $8.7 \times 10^{9} / \mathrm{cm}^{3}$, giving a porosity of 3.65 percent. A fission rate of 1.5 $\times 10^{12} \mathrm{f} / \mathrm{cm}^{3} \mathrm{sec}$ and a temperature of $430 \mathrm{C}$ were also assumed. The model does not consider the large $10 \mu \mathrm{m}$ porosity which would sinter much more slowly; consequently, it predicts much more densification than that observed. However, in both the model and the experimental observations the maximum density or minimum swelling occurs at about $1 \times 10^{20} \mathrm{f} / \mathrm{cm}^{3}$. If this densification in the experimental results is associated with the healing of the small $2 \mu \mathrm{m}$ diameter pores, theory and experiment are again in reasonable agreement. $\bar{t}$ burnups in excess of $1 \times 10^{20} \mathrm{t} / \mathrm{cm}^{3}$ both theory and data show the volume to increase due to fission gas swelling.

In the course of the breeder reactor development an experiment was conducted in which a $\mathrm{ThO}_{2}$ specimen was irradiated at a center line temperature of $1470 \mathrm{C}$ with a surface temperature of $570 \mathrm{C}$ to a depletion of $3.5 \times 10^{20} \mathrm{f} / \mathrm{cm}^{3}$.* The initial density was 93 percent, the initial grain size was about $4.5 \times 10^{-3} \mathrm{~cm}$, and the initial average pore size was about $2 \mu \mathrm{m}$ in diameter. Under these 


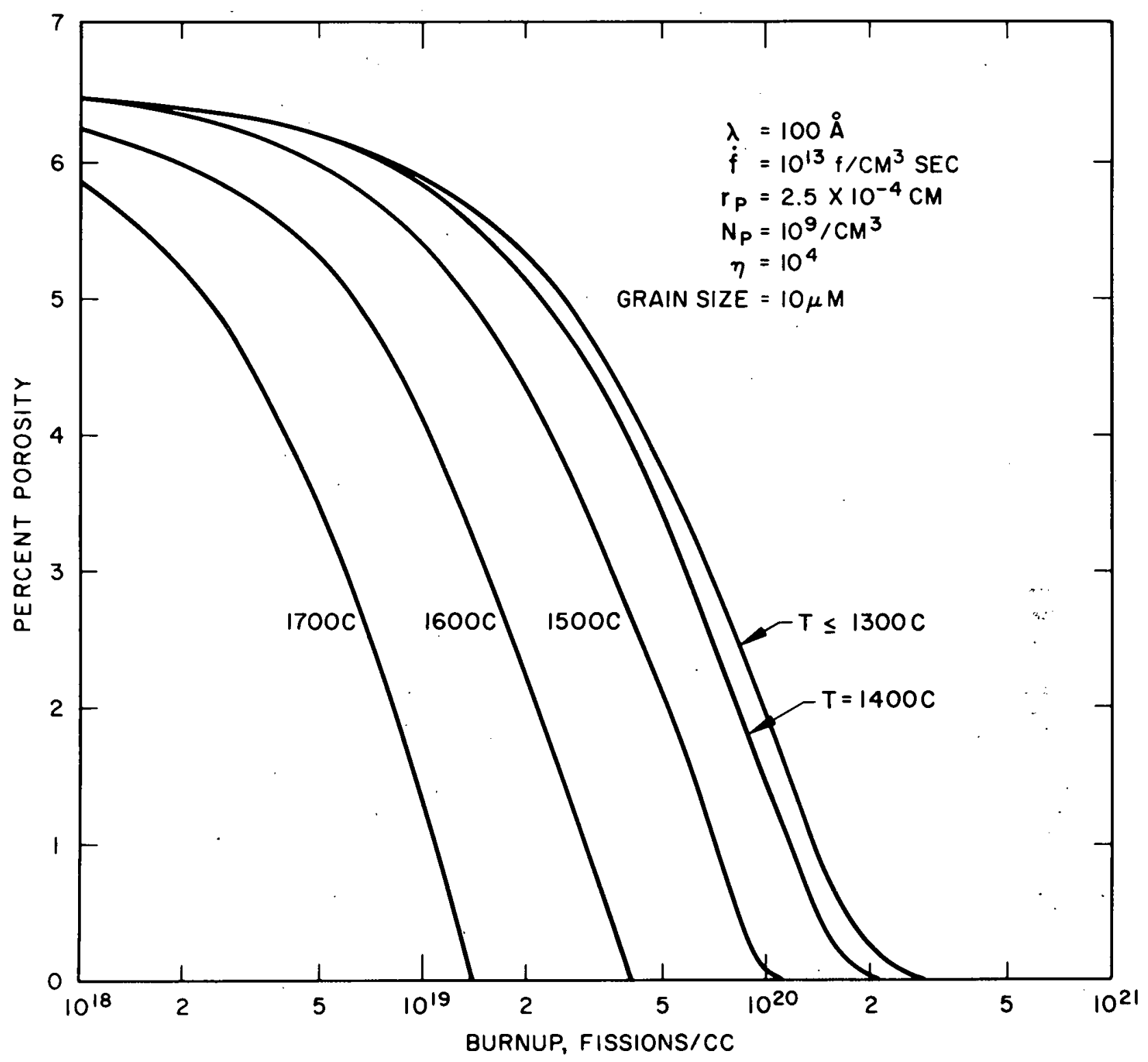

Figure 2. Percent Porosity versus Burnup for $\mathrm{UO}_{2}$ at Different Temperatures Assuming Vacancy Knockout from Pores by Fission Fragments 


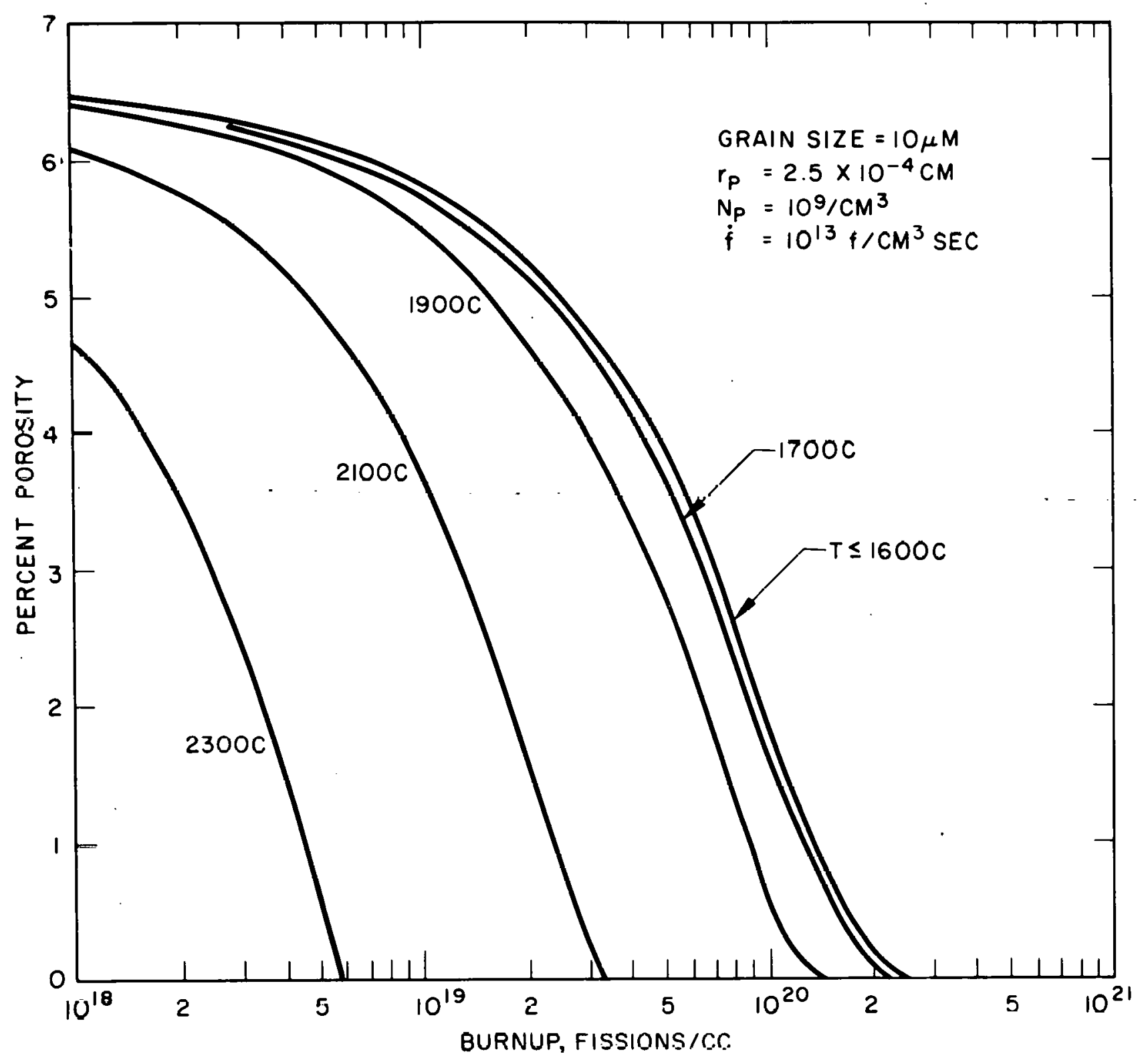

Figure 3. Percent Porosity versus Burnup for $\mathrm{Th}_{\mathrm{h}} \mathrm{O}_{2}$ at Different Temperaturcs Assuming Vacancy Knockout from Pores by Fission Fragments

8 


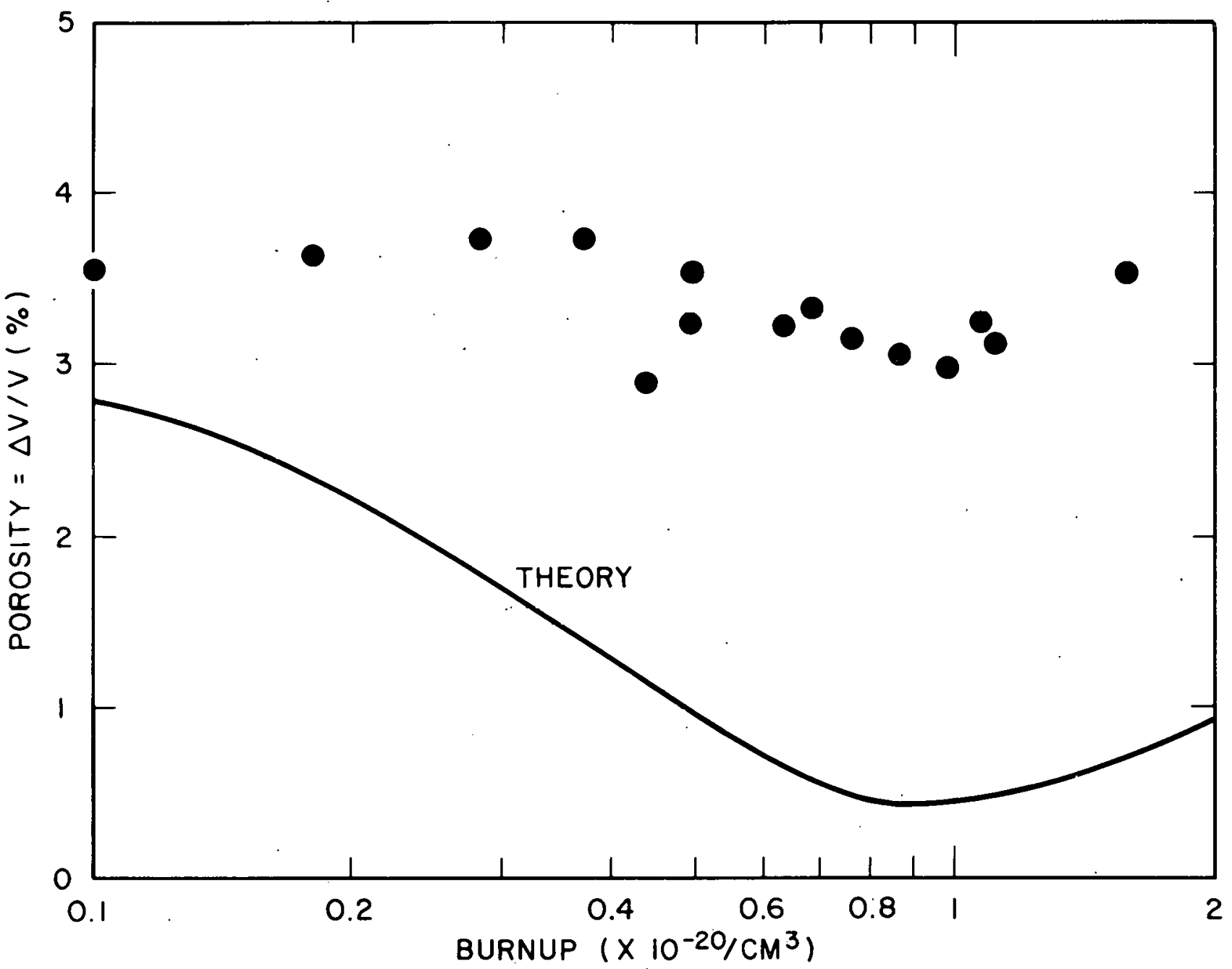

Figure 4. Comparison between Theoretical Predictions and Reference 13 Data for Densification and Swelling in $\mathrm{UO}_{2}$

conditions the volume was observed to decrease 2.9 percent and about $l$ percent of the fission gas generated was released. The model presented in this report predicted a decrease in volume of 4 percent and a fission gas release of 2.5 percent. Therefore, both the densification and gas release predictions are within the experimental accuracy of the measurements. Figure 5 shows comparisons between the data and theory.

\section{SWELLING PREDICTIONS FOR $\mathrm{ThO}_{2}$}

Figure 6 is a plot of the predicted swelling versus burnup for $\mathrm{ThO}_{2}$ assuming an initial fabricated pore size of $5 \mu \mathrm{m}$, a pore density of $1 \times 10^{9} / \mathrm{cm}^{3}$, and a grain size of $10 \mu \mathrm{m}$. The fission rate is taken to be $10^{13} \mathrm{f} / \mathrm{cm}^{3} \mathrm{sec}$. At $1000 \mathrm{C}$ swelling due to gas bubble formation described in Reference 12 becomes significant and the specimen begins to swell. At $1400 \mathrm{C}$ the resultant swelling is analogous to the $1000 \mathrm{C}$ behavior, except that at a burnup of about $6 \times 10^{20} \mathrm{f} / \mathrm{cm}^{3}$ grain boundary edge and grain boundary corner bubbles become large enough to cause the formation of inter-connected tunnels along the grain edges (Reference 14). Gas release then occurs and the swelling rate falls off considerably. This behavior holds at $1600 \mathrm{C}$, while at $1800 \mathrm{C}$ tunnel formation takes place before pore healing is completed, resulting in a pronounced cusp.

Figure 7 shows the predicted effect of grain size on densification and swelling of $\mathrm{ThO}_{2}$. The predictions are for an initial pore size of $5 \mu \mathrm{m}$, a pore density of $1 \times 10^{9} / \mathrm{cm}^{3}$, a temperature of $1000 \mathrm{C}$, and a fission rate of $1 \times 10^{13} \mathrm{f} / \mathrm{cm}^{3}$ sec. The grain size has no effect on the rate of pore healing. However, since the grain boundaries tend to collect and concentrate the fission gas atoms and thereby produce larger bubbles, the swelling increases with decreasing grain size. 


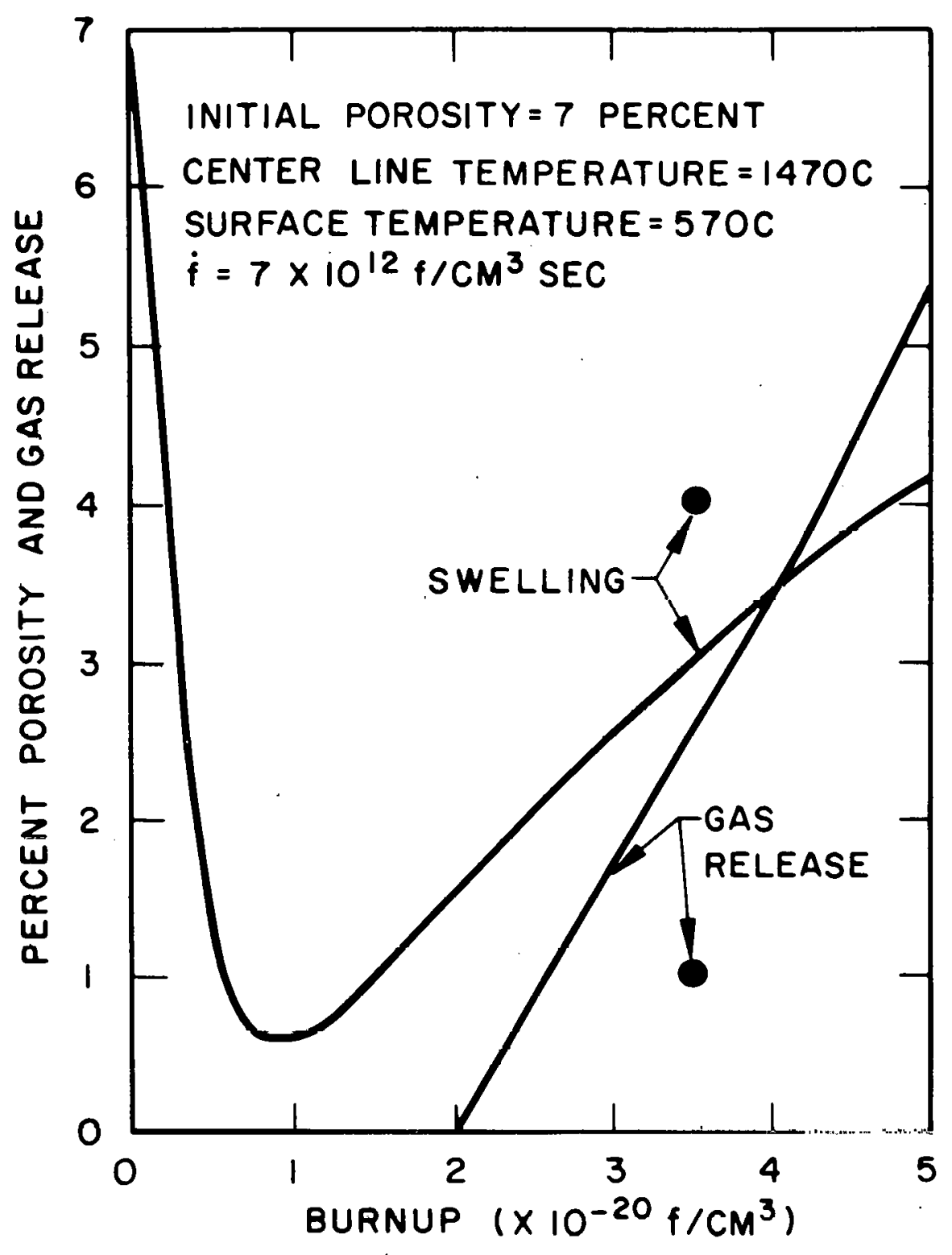

Figure 5. Comparison between Theoretical Predictions and Swelling and Gas Release Data for $\mathrm{ThO}_{2}$ 


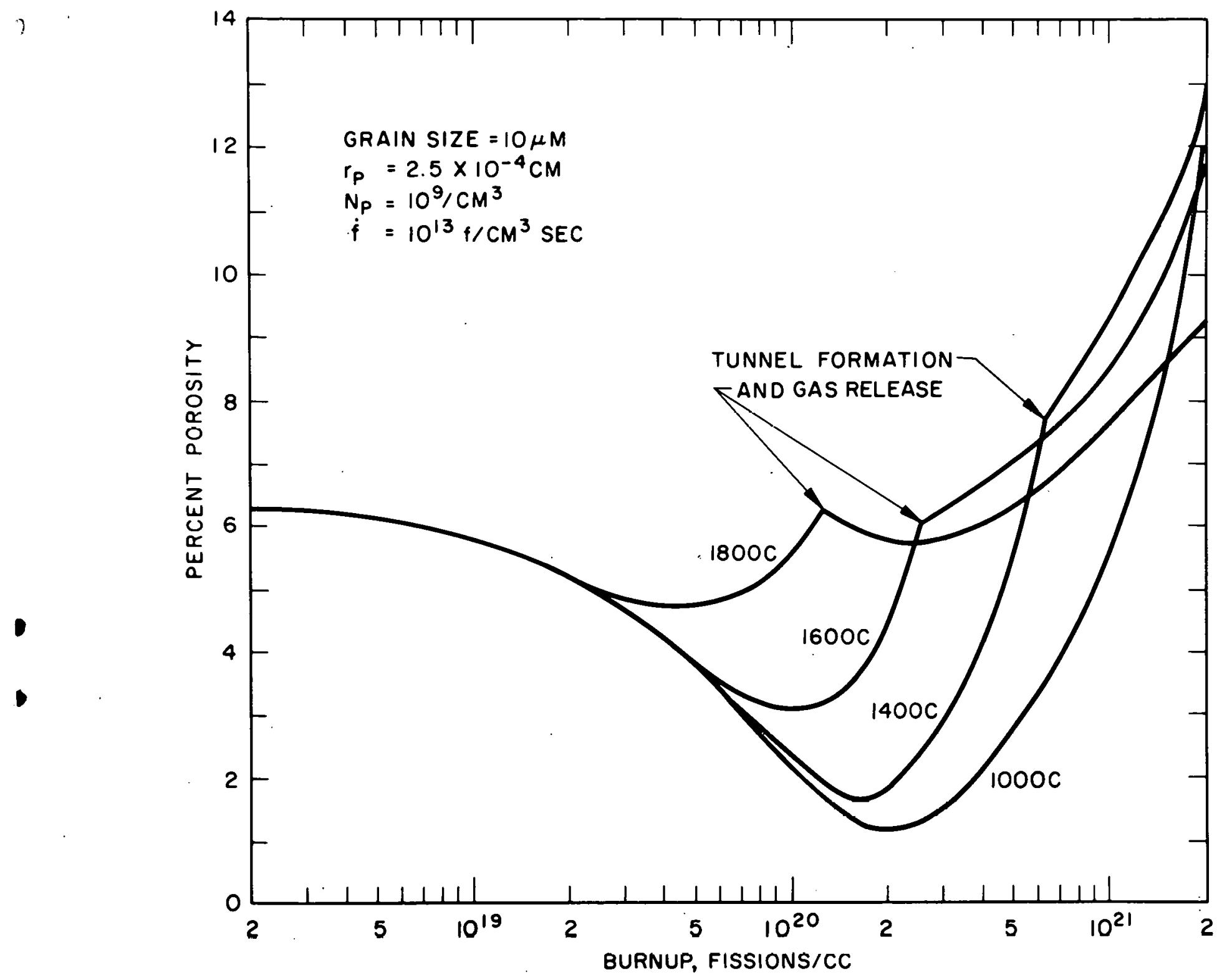

Figure 6. Model Predictions of $\mathrm{ThO}_{2}$ Swelling versus Burnup at Different Temperatures 


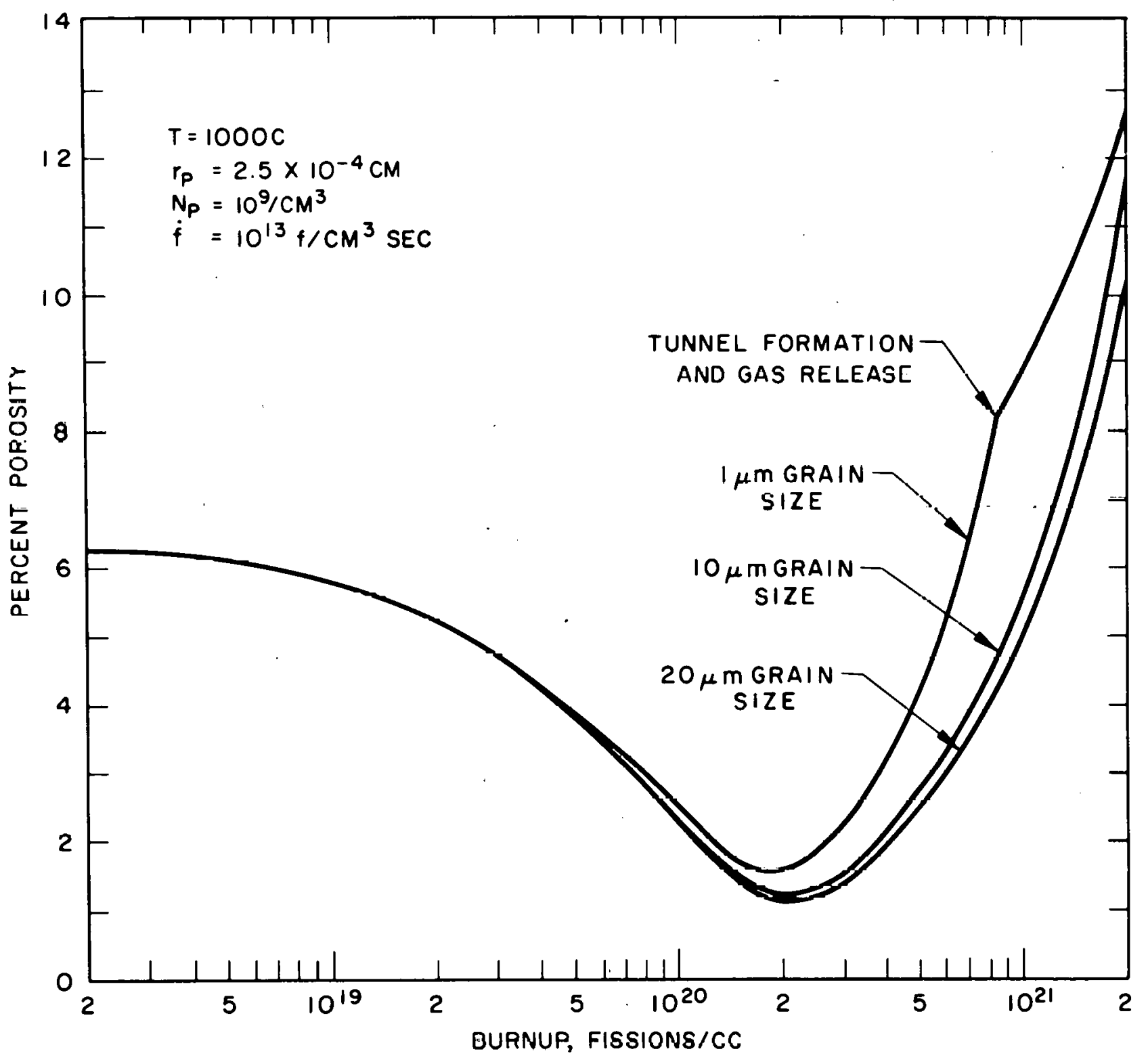

๑)

()

Figure 7. Model Predictions of $\mathrm{ThO}_{2}$ Swelling versus Burnup for Different Grain Sizes 


\section{CONCLUSION}

A model has been developed to predict intragranular densification due to thermal diffusion of point defects and due to pore destruction from fission fragment passage through the pores. The model first predicts rates of diffusion and, thus, concentrations of vacancies and interstitials. Then the rates of change of pore density and damage cascade radius are determined. These factors are coupled with the swelling and gas release model reported in Reference 12 to predict the total thermal densification of a material. Vacancy knockout by fission fragments is then factored in to predict the overall porosity versus burnup for a given fuel at varying temperatures or varying grain sizes. These predictions proved to be in close agreement with experimental data obtained under the stated conditions, and the model is now being used to predict intragranular densification of both $\mathrm{ThO}_{2}$ and $\mathrm{UO}_{2}$ fuels for water breeder reactor applications.

\section{ACKNOWLEDGMENT}

The authors wish to thank L. A. Waldman for the experimental data on $\mathrm{ThO}_{2}$ densification.

\section{REFERENCES}

1. H. Stehle and H. Assmann, J. Nucl. Mater., 52,303 (1974).

2. S. R. MacEwen and I. J. Hastings, Phil. Mag., 31,135 (1975).

3. C. C. Dollins, J. Nucl. Mater., 59, 61 (1976).

4. H. R. Warner and F. A. Nichols, Nucl. Appl. and Tech., 9, 148 (1970).

5. A. D. Brailsford and R. Bullough, "Physical Metallurgy of Reactor Fuel Elements," The Metals Society, 148, 1975.

6. A. M. Ross, J. Nucl. Mater., 30, 134 (1969).

7. A. D. Wahpham, Phil. Mag., 23, 987 (1971).

8. F. S. Ham, J. of Appl. Physics, 30, 915 (1959).

9. S. D. Harkness and C. Y. Li, Met. Trans., 2, 1457 (1971).

10. R. S. Nelson, J. Nucl. Mater., 31, 153 (1969).

11. C. C. Dollins and H. Ocken, Nucl. Appl. and Tech., 9, 141 (1970).

12. C. C. Dollins and F. A. Nichols, J. Nucl. Mater., 66, 143 (1977).

13. D. A. Banks, J. Nucl. Mater., 54, 97 (1974).

14. J. A. Turnbull and M. O. Tucker, Phil. Mag., 30,47 (1974).

15. J. Belle, ed., "Uranium Dioxide: Properties and Nuclear Applications," Naval Reactors, Div. of Reactor Dev. USAEC (1950).

16. D. S. Maiya, J. Nucl. Mater., 40, 57 (1971).

17. H. R. Warner and R. C. Daniel, ANS Trans., 14,148 (1971). 